\title{
How useful is esophageal high resolution manometry in diagnosing gastroesophageal junction disruption: Causes affecting this disruption and its relationship with manometric alterations and gastroesophageal reflux
}

\author{
Constanza Ciriza-de-los-Ríos ${ }^{1}$, Fernando Canga-Rodríguez-Valcárcel ${ }^{1}$, Isabel Castel-de-Lucas ${ }^{1}$, \\ David Lora-Pablos ${ }^{2}$, Javier de-la-Cruz-Bértolo ${ }^{2}$ and Gregorio Castellano-Tortajada ${ }^{1}$
}

${ }^{I}$ Department of Gastroenterology. Hospital Universitario 12 de Octubre. Madrid, Spain. ${ }^{2}$ Clinical Research Unit, IMAS12-CIBERESP. Hospital Universitario 12 de Octubre. Madrid, Spain

\begin{abstract}
Background: High-resolution manometry (HRM) is a breakthrough in the morphological study of the gastroesophageal junction (GEJ) and its degrees of disruption.

Objectives: a) Assessment of risk factors involved in the disruption of the GEJ in patients with gastroesophageal reflux (GER) symptoms; b) the relationship between the type of GEJ and GER demonstrated by 24 hours $\mathrm{pH}$-monitoring; and c) identification of the alterations in the manometric parameters related to the morphology of the GEJ.

Methods: One hundred and fifteen patients with symptoms of GER studied with HRM and classified by the type of GEJ (type I: Normal; type II: Sliding; type III: Hiatal hernia). Twenty four hour $\mathrm{pH}$-monitoring without proton pump inhibitors was performed in all of them. Epidemiological aspects, manometric parameters (Chicago 2012 classification) and the $\mathrm{pH}$-monitoring results were evaluated.

Results: Age (OR 1.033 [1.006-1.060]; $p=0.16$ ), BMI (OR 1.097 [1.022-1.176]; $\mathrm{p}=0.01$ ) and abdominal perimeter (OR 1.034 [1.005-1.063]; $\mathrm{p}=0.0215$ ) were independent risk factors for the GEJ type III (area under the curve 0.70). Disruption of the GEJ was associated with a lower resting pressure $(p=0.006)$, greater length $(p<0.001)$ and greater esophageal shortening $(p$ $<0.001$ ). Abnormal acidic reflux was found in the total period ( $p$ $=0.015)$, standing $(p=0.022)$ and supine $(p=0.001)$ in patients with GEJ type II and III with respect to type I.

Conclusions: Increased age, overweight and central obesity pose a higher risk of GEJ type III (hiatal hernia). The greater disruption of the GEJ is associated with lower resting pressure, esophageal shortening, and higher acid exposure in the pH-monitoring.
\end{abstract}

Key words: Esophageal high resolution manometry. Gastroesophageal junction. Hiatal hernia. Gastroesophageal reflux.

Received: 06-05-2013

Accepted: 12-11-2013

Correspondence: Constanza Ciriza de los Ríos. Department of Gastroenterology. Hospital Universitario 12 de Octubre. Avenida de Córdoba s/n. 28041 Madrid, Spain

e-mail: constanzacarpa@gmail.com
Ciriza-de-los-Ríos C, Canga-Rodríguez-Valcárcel F, Castel-de-Lucas I, Lora-Pablos D, De-la-Cruz-Bértolo J, Castellano-Tortajada G. How useful is esophageal high resolution manometry in diagnosing gastroesophageal junction disruption: Causes affecting this disruption and its relationship with manometric alterations and gastroesophageal reflux. Rev Esp Enferm Dig 2014;106:22-29.

\section{INTRODUCTION}

The gastroesophageal junction (GEJ) is a complex structure that regulates, in a coordinated manner, the passage of food to the stomach and prevents the retrograde movement of gastric content that is potentially harmful to the esophagus.

The lower esophageal sphincter (LES) is not only a thickening of the circular smooth muscle layer, but it also features other muscles with different physiological characteristics. Thus, the intrinsic musculature of the GEJ is formed by semicircular smooth muscle fibers with a constant myogenic tone (mediated by the myenteric plexus) and gastric sling fibers on its left side portion, with low basal tone although they contract with cholinergic stimulation (1). Whereas the extrinsic muscles that are composed of the crural diaphragm (CD), embracing the LES, increases the pressure on the GEJ during inspiration (2). Under normal circumstances, the esophagus is anchored to the diaphragm in a way that prevents displacement of the stomach through the diaphragmatic hiatus towards the mediastinum. The main restraining structures are the phrenoesophageal ligaments also known as phrenoesophageal membrane. In addition to its role in maintaining the fixation of the esophagogastric region to the diaphragm, the phrenoesophageal membrane also closes the virtual space between the esophagus and diaphragm, making it a key structure in the pathogenesis of the hiatal hernia. With age, elastic tissue of the phrenoesophageal membrane 
decreases progressively, increasing its laxity and favoring the disruption of the GEJ (3). This causes, to a greater or lesser extent, the separation of the LES and the DC, leading to the ultimate expression of this phenomenon as the hiatal hernia. This separation reduces the competence of the gastroesophageal barrier favoring gastroesphageal reflux (GER) (4) and also causes the alteration of esophageal motility (5).

High resolution manometry (HRM) is useful for the correct identification and detection of the different degrees of disruption of the GEJ (6-8). Three subtypes of GEJ are identified according to their morphology and extent of disruption from a manometric point of view (9).

The objectives of this study were: a) Rating the risk factors involved in the disruption of the GEJ in patients with GER; b) identifying the relationship between the type of GEJ and GER demonstrated by 24 hours $\mathrm{pH}$-monitoring; and c) identification of the alterations in the manometric parameters related to the morphology of the GEJ.

\section{MATERIAL AND METHODS}

\section{Patients and inclusion criteria}

This is a transversal and observational study from January 2012 to February 2013. During this period, 155 patients with typical and atypical GER symptoms were prospectively included.

Inclusion criteria were: a) Informed consent obtained; b) minimum age of 18 years; c) exclusion of organicity by barium esophagogram study or upper endoscopy; and d) completion of GER symptoms questionnaire.

The patient's symptoms were recorded using a standard questionnaire, considering typical GER symptoms such as the presence of heartburn or regurgitation at least once a week. GER atypical symptoms that were included were: a) Atypical ear nose and throat (ENT): Dysphonia and pharyngeal globus, defined as a feeling of pharyngeal foreign body with a frequency of at least once a week; $b$ ) pulmonary: Frequent chronic cough (at least 4 times a day, 4 days or more per week); and c) non cardiac chest pain defined as retrosternal pain different from heartburn with a frequency of at least once a week.

Exclusion criteria were: a) Patients referring esophageal dysphagia with concomitant symptoms of reflux, as the correlation between esophageal motor disorder and symptoms of reflux are not very consistent (10); b) previous surgical or endoscopic treatments on the GEJ; and c) patients that refused to sign the informed consent.

With these criteria 30 patients with esophageal dysphagia and 10 patients who had undergone treatments on the GEJ were excluded, so the final number of patients included in the study was 115 .

The study was approved by the Ethical Committee of the Hospital Universitario 12 de Octubre.

\section{Protocol for esophageal high-resolution manometry}

HRM was performed by using a solid-state manometric assembly with 36 circumferential sensors spaced at $1-\mathrm{cm}$ intervals and outer diameter of $4.2 \mathrm{~mm}$ (Given Scientific Instruments Inc, Los Angeles, CA, USA). Prior to recording, the transducers were calibrated at 0 and $300 \mathrm{~mm} \mathrm{Hg}$ using externally applied pressure. After confirmation of potential allergies, topical viscous lidocaine $5 \%$ was applied to numb the nares followed by tans-nasal catheter insertion.

Manometric studies were performed on basal conditions (after withholding medication known to affect gastrointestinal function) and in supine, obtaining a simultaneous recording from the hypopharynx to the stomach with at least three intragastric sensors. After 5 minutes the patient became accustomed to the probe, the recording started with a 30 -s basal period without swallowing to obtain the upper esophageal sphincter and GEJ pressures followed by ten $5-\mathrm{mL}$ swallows at 20 second intervals (11), rejecting those swallows in which the patient swallowed twice or the interval between swallows was less than 20 seconds, to finally obtain ten swallows interpretable for the analysis (12).

\section{4 hour pH-monitoring protocol}

Double channel 24-hour ambulatory $\mathrm{pH}$-monitoring without proton pump inhibitors (PPI) treatment was performed with a two channels catheter that were placed $5 \mathrm{~cm}$ and $20 \mathrm{~cm}$ respectively, above the upper limit of the GEJ. The study catheter was attached to an ambulatory recorder (Matla Systems Inc, Madrid, Spain). The patients were encouraged to maintain normal activity, sleep schedule, and their dietary routine at their normal times. A diary was provided for each patient to record the time and duration of meals, posture changes and symptoms.

\section{Data analysis}

The following epidemiological and clinical data were obtained: a) Demographics: Age, sex, weight and height to calculate the body mass index (BMI), abdominal perimeter length; c) life habits: Tobacco, alcohol and coffee intake; c) medical history; d) prior consumption of PPI; and e) symptoms of GER.

Manometric data were analyzed using Mano View ${ }^{\mathrm{TM}}$ software version 3.0 (Given Scientific Instruments Inc. The Angeles, CA, USA). The GEJ were classified into type I (CD is completely overlapped with LES), type II (sliding: Separation of 1-2 cm between CD and LES) and type III (hiatal hernia: Separation between CD and LES exceeds $2 \mathrm{~cm}$ ) (9) (Fig. 1). The separation between the LES and 
the $\mathrm{CD}$ was measured at the inspiratory peak. End expiratory EGJ pressure was measured during the basal period with the absence of swallowing, and then referenced to the intra-gastric pressure. The cases with large hiatal hernias in which the CD pressure mark was not identified, the reference used was atmospheric pressure using the "smart mouse" tool provided by the software Mano View ${ }^{\mathrm{TM}}$ version 3.0. Integrated relaxation pressure within 4 seconds (IRP-4s) was measured using automated analysis tool with the same software, defined as the lowest average residual pressure for 4 contiguous or non contiguous seconds within the post swallow period during 10 swallows. IRP-4s normal value has been defined as less than $15 \mathrm{~mm} \mathrm{Hg}$ in supine (6).

The following manometric parameters were evaluated: a) LES: Mean basal and IRP-4s, total, intra-abdominal and intra thoracic length GEJ length. In GEJ type III, the length of the LES, CD and hernia sac were measured; and b) esophageal body (EB): Length, percentage of peristaltic, simultaneous, failed and premature contractions, mean distal contractile integral (DCI), contractile front velocity (CFV), intrabolus pressure (IBP) and distal latency (DL).

Two experienced investigators performed HRM and analyzed the HRM plots obtained for each patient. With the parameters obtained from them a final diagnosis of LES, EGJ morphology and EB was provided according to the diagnostic criteria proposed by the Chicago group (2012 classification) (13).

LES diagnosis was divided into four groups for analysis as normal, hypotensive, hypertensive and GEJ functional obstruction. Hypotensive LES was considered when resting LES pressure was $<10 \mathrm{~mm} \mathrm{Hg}$ and normal IRP-4s $(<15 \mathrm{~mm} \mathrm{Hg})$ and hypertensive when LES resting pressure was $>35 \mathrm{~mm} \mathrm{Hg}$ and normal IRP-4s. Functional obstruction was considered when IRP-4s $>15 \mathrm{~mm} \mathrm{Hg}$ in supine.

The subgroups for weak peristalsis that included small and large peristaltic breaks and frequent failed peristalsis were considered together for analysis purposes.

Data obtained from the $\mathrm{pH}$ monitoring were: Percentage of time $\mathrm{pH}<4$ total period; percentage of time $\mathrm{pH}$ $<4$ in the upright position; percentage of time $\mathrm{pH}<4$ in the supine position, in both distal and proximal channels; DeMeester score and the symptomatic index. For the analysis, the normal values reported by DeMeester were used (14). The symptomatic index was used to correlate the symptoms and the episodes of reflux, requiring at least 5 symptomatic episodes for analysis and it was considered positive if $\geq 50 \%$.

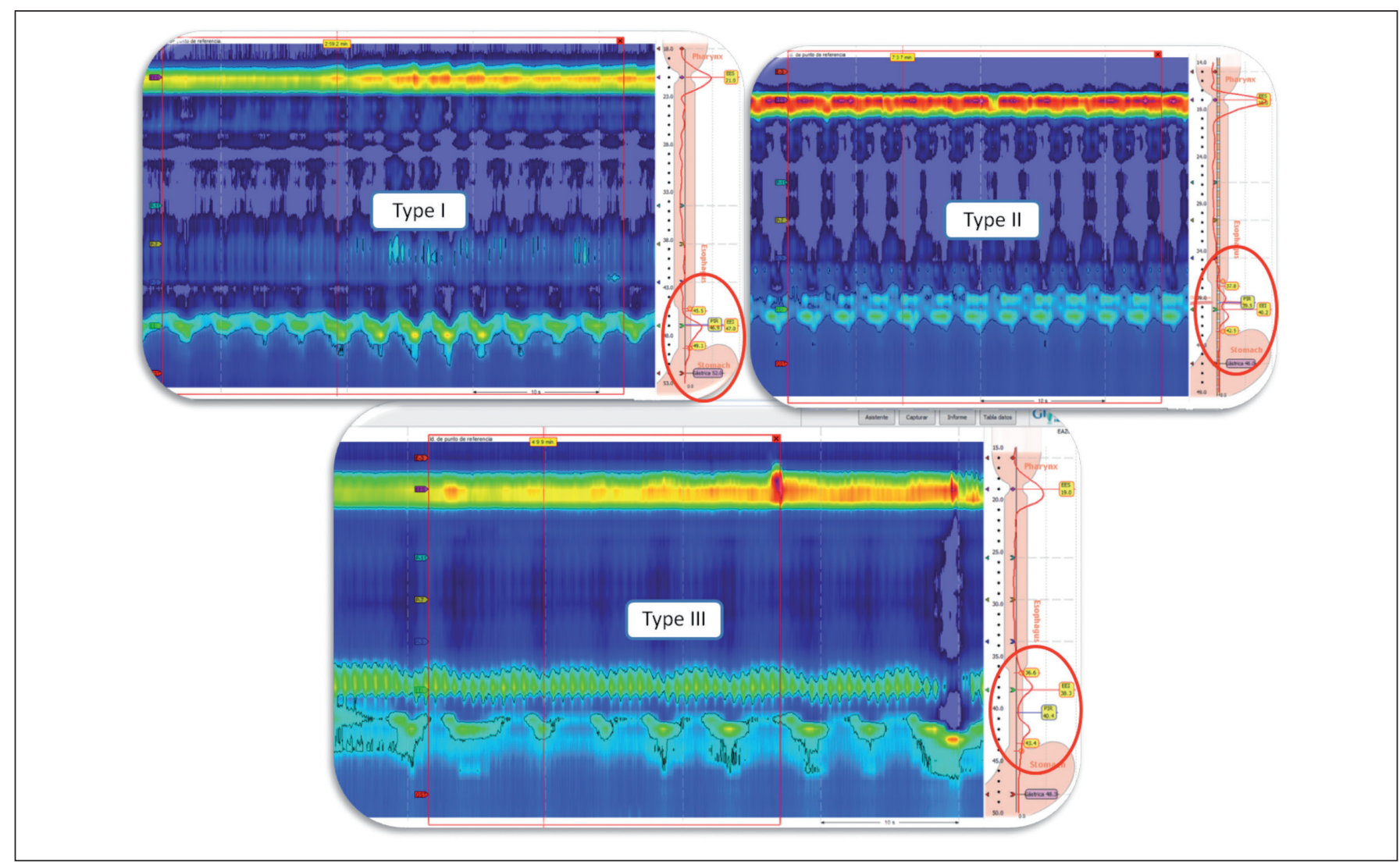

Fig. 1. Topographic plots of the different GEJ by high resolution manometry. 
Table I. Epidemiological and clinical data according to the GEJ type

\begin{tabular}{|c|c|c|c|c|}
\hline & GEJ I $(n=56)$ & GEJ $/ /(n=44)$ & GEJ III $(n=15)$ & $p$ value \\
\hline Age & $49.3[45.4-53.2]$ & $54.3[49.6-58.9]$ & $64.9[58.5-66]$ & 0.001 \\
\hline $\operatorname{Sex}(F)$ & $33(58.9 \%)$ & $28(63.6 \%)$ & $10(66.7 \%)$ & 0.815 \\
\hline BMI $\left(k g / m^{2}\right)$ & $25.2[23.9-26.4]$ & 27.9 [26.3-29.7] & $31.4[25.4-37.4]$ & 0.001 \\
\hline Abdominal perimeter $(\mathrm{cm})$ & $88.5[84.8-92.2]$ & 95.6 [91.5-99.6] & 98.4 [92.6-104.2] & 0.003 \\
\hline Tobacco (cigarettes/day no.) & $1.6[0.4-2.8]$ & $1.5[0.3-2.8]$ & $1[-1.1-3.1]$ & 0.594 \\
\hline $\begin{array}{l}\text { Alcohol (g/day) } \\
\text { Non drinker } \\
<40 \mathrm{~g} \text { ethanol } \\
40-80 \mathrm{~g}\end{array}$ & $\begin{array}{l}45(80.4 \%) \\
10(17.9 \%) \\
1(1.8 \%)\end{array}$ & $\begin{array}{l}35(79.5 \%) \\
9(20.5 \%) \\
0\end{array}$ & $\begin{array}{l}10(66.7 \%) \\
5(33.3 \%) \\
0\end{array}$ & 0.606 \\
\hline $\begin{array}{l}\text { Coffee (cups/day) } \\
\text { No } \\
1-2 \text { cups } \\
2 \text { cups }\end{array}$ & $\begin{array}{l}27(48.2 \%) \\
25(44.6 \%) \\
4(7.1 \%)\end{array}$ & $\begin{array}{l}10(22.7 \%) \\
26(59.1 \%) \\
8(18.2 \%)\end{array}$ & $\begin{array}{l}6(40 \%) \\
7(46.7 \%) \\
2(13.3 \%)\end{array}$ & 0.097 \\
\hline $\begin{array}{l}\text { Comorbidity } \\
\text { No } \\
\text { Yes }\end{array}$ & $\begin{array}{l}21(37.5 \%) \\
35(62.5 \%)\end{array}$ & $\begin{array}{l}9(20.5 \%) \\
35(79.5 \%)\end{array}$ & $\begin{array}{l}2(13.3 \%) \\
13(86.7 \%)\end{array}$ & 0.068 \\
\hline $\begin{array}{l}\text { Prior IBP } \\
\text { No } \\
\text { Yes }\end{array}$ & $\begin{array}{l}6(10.7 \%) \\
50(89.3 \%)\end{array}$ & $\begin{array}{l}5(11.4 \%) \\
39(88.6 \%)\end{array}$ & $\begin{array}{l}1(6.7 \%) \\
14(93.3 \%)\end{array}$ & 0.872 \\
\hline $\begin{array}{l}\text { Type GERD symptoms } \\
\text { Typical } \\
\text { Typical and atypical } \\
\text { Atypical ENT/pulmonary } \\
\text { NCP }\end{array}$ & $\begin{array}{l}23(41.1 \%) \\
6(10.7 \%) \\
18(32.1 \%) \\
9(16.1 \%)\end{array}$ & $\begin{array}{l}28(63.7 \%) \\
3(6.8 \%) \\
10(22.7 \%) \\
3(6.8 \%)\end{array}$ & $\begin{array}{l}12(80 \%) \\
1(6.7 \%) \\
0 \\
2(13.3 \%)\end{array}$ & 0.054 \\
\hline
\end{tabular}

BMI: Body mass index; PPI: Proton pump inhibitors; ENT: Ear, nose and throat; GERD: Gastroesophageal reflux disease; NCP: Non cardiac chest pain.

\section{Statistical analysis}

Descriptive analyses of the qualitative and quantitative variables mentioned, were performed. Qualitative variables were described using absolute frequency and percentages, while quantitative variables were expressed as mean and confidence interval (CI) $9 \%$.

For comparisons of quantitative variables according to the GEJ type the Kruskal-Wallis test was used for independent data. When statistical significance was achieved, the Mann-Whitney test was used to compare pairs correcting the $p$-value. For categorical variables the Chi-square test or Fisher's exact test, when appropriate, were applied. Using ordinal logistic regression models the clinical and epidemiological factors that might influence the hiatal hernia were estimated in a univariate form, obtaining the crude odds ratio, and in a multivariate form the odds ratio adjusted for each of the variables that were part of the model were obtained. Due to the relationship between BMI and abdominal perimeter, two different models were built excluding in each model one of the two variables. To assess the relationship between the length of the hernia sac, and the esophageal body a linear regression model was used. The level of significance was established at $5 \%$. Analyses were performed using the statistical program SPSS 18.0.

\section{RESULTS}

The epidemiological and clinical characteristics according to the GEJ type are expressed in table I. The disruption of the GEJ, manifested by the separation between the LES and the CD is associated with older age $(p=0.001)$, overweight $(p=0.001)$ and central obesity (abdominal perimeter $)(p=0.003)$. Patients with GEJ type I had a higher frequency of atypical GER symptoms compared to patients with GEJ type II or type III where typical GER symptoms were more predominant $(p=0.054)$. In the univariate analysis, the older age, the higher BMI and abdominal perimeter and more comorbidity were associated with an increased risk of having GEJ type III (hiatal hernia) (Table II). In the multivariate analysis, independent risk factors for GEJ type III were older age and higher BMI (Table II), resulting in an area under the curve of 0.70 . Analyzing the other multivariate model involving the abdominal perimeter, independent risk factors for GEJ type III were ageing (OR 1.035 [1.008-1.062]; $p=0.0109)$ and 
Table II. Univariate and multivariate analysis. Risk factors associated with GEJ type III (hiatal hernia)

\begin{tabular}{|c|c|c|c|c|c|c|}
\hline \multirow[b]{2}{*}{ Risk factor } & \multicolumn{3}{|c|}{ Univariate analysis } & \multicolumn{3}{|c|}{ Multivariate analysis } \\
\hline & $O R$ & IC $[95 \%]$ & p-value & OR & IC $[95 \%]$ & $p$-value \\
\hline Age* & 1.042 & [1.016-1.069] & 0.0013 & 1.033 & [1.006-1.060] & 0.016 \\
\hline Sex & 1.265 & {$[0.615-2.600]$} & 0.5231 & & & \\
\hline $\mathrm{BMI}^{*}$ & 1.118 & [1.044-1.198] & 0.0015 & 1.097 & [1.022-1.176] & 0.01 \\
\hline Abdominal perimeter* & 1.043 & {$[1.015-1,072]$} & 0.0024 & & & \\
\hline Tobacco & 0.983 & [0.903-1.069] & 0.6833 & & & \\
\hline Alcohol & 1.437 & [0.622-3.320] & 0.3964 & & & \\
\hline Coffee & 2.063 & {$[0.980-4.342]$} & 0.0564 & & & \\
\hline Comorbidity** & 2.638 & [1.148-6.061] & 0.0223 & & & \\
\hline Prior IBP & 1.151 & {$[0.365-3.630]$} & 0.8108 & & & \\
\hline
\end{tabular}

${ }^{*} \mathrm{p}<0.01 ;{ }^{*} \mathrm{p}<0.05 ; \mathrm{BMI}$ : Body mass index; OR: Odd ratio; Cl: 95 \% confidence interval.

increased abdominal perimeter (OR 1.034 [1.005-1.063]; $\mathrm{p}=0.0215)$, resulting in an area under the curve of 0.70 .

The parameters of HRM and $\mathrm{pH}$-monitoring depending on the type of GEJ are expressed in table 3. In six cases with GEJ type III, with a large hernia sac, the identification of the CD was not possible, so LES resting pressure was referenced to atmospheric pressure, the mean resting pressure in these cases being that of 26.1 [19.6-32.6] $\mathrm{mm} \mathrm{Hg}$. Disruption of the GEJ was associated with lower resting pressure with $(\mathrm{p}=0.006)$, greater GEJ length ( $\mathrm{p}$ $<0.001$ ) and a further shortening of the esophagus ( $\mathrm{p}<$ 0.001) respect to GEJ type I (Table III). In those patients with GEJ type III, the average LES length was $2.5 \mathrm{~cm}$ [2-2.9]; average CD length $2.1 \mathrm{~cm}$ [1.8-2.5] and hernia sac length $3.9 \mathrm{~cm}$ [2.5-5.2], noting that the increase of one unit in the length of the hernia sac decreases the length of the esophagus in 0.963 ( $\mathrm{p}=0.013$ ) (Fig. 2).

GEJ type II group showed more hypotonia and GEJ type III (hiatal hernia) group a higher degree of functional obstruction ( $\mathrm{p}=0.056$ ) compared to GEJ type I group (Fig. 3 ). There were no significant differences in the final diagnosis for esophageal body among the studied groups (Fig. 3).

Greater acid exposure was found at the level of the distal esophagus during total $(p=0.015)$, upright $(p=0.022)$ and supine $(\mathrm{p}=0.001)$ periods in patients with GEJ type II and III than in patients with GEJ type I (Table III), without significant differences observed in the proximal esophagus. In patients with GEJ type II and III the $\mathrm{pH}$-monitoring result was frequently abnormal (Fig. 4). There were no differences in the symptomatic index between the groups $(\mathrm{p}=0.509)$.

\section{DISCUSSION}

The GEJ is a structure dependent on the close anatomical relationship between the distal esophagus, the diaphragmatic hiatus and the stomach. It is important to recognize that this relationship is not static, and a physiological "herniation" can occur during primary or secondary peristalsis, esophageal distension, and the temporary relaxation of the LES $(3,15)$. This mobility depends on the contractile activity of esophageal longitudinal muscle and the integrity and elastic properties of the phrenoesophageal membrane $(16,17)$. As a result, it is difficult to measure the sliding hiatal hernia, because its diagnosis is not standardized and variability in its measurement between the different methods of detection such as barium radiology, upper endoscopy and manometry exists $(3,18)$. However, HRM allows an efficient assessment of the normal GEJ and different levels of disruption including hiatal hernia, which is important for its involvement in gastroesophageal reflux disease (GERD) (19). In our study, patients with GEJ disruption generally had typical GER symptoms compared to those with normal GEJ, so that the different types of GEJ were related to a different form of symptomatic presentation of GERD.

Both age and obesity are factors frequently involved in hiatal hernia $(3,20)$. Our results also confirmed that ageing, overweight and central obesity are the independent risk factors for the disruption of the GEJ. Different degrees of disruption of the GEJ, especially the hiatal hernia, were found also to be associated with GER (4). In our study, patients with GEJ type II and particularly those with type III, had a greater acid exposure in the distal esophagus, especially during the night, though disruption of the GEJ did not influence the proximal extent for GER.

It has been described that the presence of a large hiatal hernia modifies the values of the measurement parameters for HRM in the body of the esophagus, so patients with large hiatal hernia have lower average LES pressures, lower DCI, slower CFV and shorter DL (5). We also confirmed these findings in the GEJ type III with respect to the other types of GEJ. These changes appear to be related 
Table III. HRM and pH-monitoring parameters according to GEJ type

\begin{tabular}{|c|c|c|c|c|}
\hline \multicolumn{5}{|c|}{ HRM parameters } \\
\hline & $G E J /(n=56)$ & $G E J \|(n=44)$ & GEJ III $(n=15)$ & $p$ value \\
\hline Resting pressure (mm Hg) & $16.3[13.8-18.8]$ & $10.6[9-12.3]$ & $13.9[9.8-18.1]$ & 0.006 \\
\hline IRP-4s & $8.7[7.4-9.9]$ & $7.5[3.5-8.9]$ & $11.3[7.9-14.7]$ & 0.133 \\
\hline GEJ total length $(\mathrm{cm})$ & $4[3.9-4.2]$ & $4.7[4.5-4.9]$ & $8.5[6.9-10.2]$ & $<0.001$ \\
\hline Abdominal length $\mathrm{cm}$ ) & $2.3[2.2-2.4]$ & $2.1[1.9-2.3]$ & & 0.003 \\
\hline Thoracic length $(\mathrm{cm})$ & $1.8[1.7-1.9]$ & $2.5[2.2-2.8]$ & & 0.594 \\
\hline Esophageal body length & $24.6[24.1-25.1]$ & $23.6[23-24.1]$ & $20.5[18.5-22.4]$ & $<0.001$ \\
\hline $\mathrm{DCl}(\mathrm{mm} \mathrm{Hg} . \mathrm{cm} . \mathrm{s})$ & $\begin{array}{l}2525.5[2063.7- \\
2987.4]\end{array}$ & $\begin{array}{l}\text { 1981.4[1537.9- } \\
2424.9]\end{array}$ & $\begin{array}{l}1865.4 \text { [1159.7- } \\
2570.9]\end{array}$ & 0.204 \\
\hline CFV $(\mathrm{cm} / \mathrm{s})$ & $4.9[3.1-6.7]$ & $4.1[3.1-5.1]$ & $2.9[2.5-3.4]$ & 0.027 \\
\hline $\mathrm{IBP}(\mathrm{mm} \mathrm{Hg})$ & 24.6 [20.7-28.5] & $19.3[16.9-21.5]$ & $21.3[17.1-25.5]$ & 0.136 \\
\hline $\mathrm{DL}(\mathrm{s})$ & $6.3[5.7-6.9]$ & $6.9[5.6-8.3]$ & $5.8[2.4-14.1]$ & 0.577 \\
\hline Peristaltic \% & 88.6 [82.9-94.2] & 87.2 [81.1-93.2] & 98.7 [96.7-100.6] & 0.066 \\
\hline Simultaneous \% & $5.9[2-9.7]$ & $6.2[1.7-10.7]$ & $0.67[-0.8-2.1]$ & 0.290 \\
\hline \multirow[t]{3}{*}{ Failed \% } & $5.5[2.3-8.8]$ & $6.9[3.3-10.7]$ & $0.67[-0.8-2.1]$ & 0.141 \\
\hline & \multicolumn{3}{|c|}{24 hours $p H$-monitoring parameters } & \\
\hline & $G E J /(n=56)$ & GEJ $/ /(n=44)$ & GEJ III $(n=15)$ & $p$ value \\
\hline$\% \mathrm{pH}$ total distal & $2.3[1.6-2.9]$ & $4.9[3.6-6.4]$ & $8.1[3.4-12.8]$ & 0.015 \\
\hline$\%$ pH upright distal & $2.6[1.9-3.4]$ & $5.9[4.3-7.6]$ & $7.2[3.2-11.3]$ & 0.022 \\
\hline$\% \mathrm{pH}$ supine distal & $1.3[0.6-2.1]$ & $3.8[1.8-5.8]$ & $8.9[2.5-15.2]$ & 0.001 \\
\hline$\% \mathrm{pH}$ total proximal & $0.6[0.4-0.9]$ & $0.8[0.5-1.1]$ & $0.5[0.1-0.9]$ & 0.811 \\
\hline$\% \mathrm{pH}$ upright proximal & $0.7[0.4-1]$ & $1.2[0.7-1.7]$ & $0.9[0.1-1.7]$ & 0.594 \\
\hline$\% \mathrm{pH}$ supine proximal & $0.4[0-0.8]$ & $0.1[0-0.2]$ & $0.1[0-0.2]$ & 0.985 \\
\hline DeMeester distal & $9.8[6.6-13]$ & $19.8[14.2-25.3]$ & $30.9[13.6-48.3]$ & 0.014 \\
\hline DeMeester proximal & $3.3[2.1-4.4]$ & $3.8[2.5-5.1]$ & $2.7[1.1-4.3]$ & 0.700 \\
\hline
\end{tabular}

IRP-4s: 4 second integrated relaxation pressure; DCI: Distal contractile integral; CFV: Contractile front velocity; IBP: Intrabolus pressure; DL: Distal latency.

to a reduced esophageal length found in these patients (5), also confirmed by this study. However, despite these variations in the manometric parameters, the final diagnosis for esophageal body was not modified which coincides with previous reports (5). However, this fact may be conditioned by the small size of our sample for GEJ type III. On the other hand, the disruption of the GEJ can decrease its resting pressure. In this sense, we found significant differences between the patients with normal GEJ, and those who had some degree of disruption as the type II group which presented more hypotonic LES. In addition, some hiatal hernias may cause outflow obstruction caused by the anatomical distortions at the GEJ (21). In our study, a higher incidence of outflow obstruction was encountered in patients with hiatal hernia compared to the other GEJ type groups. This finding could have a relationship to a certain degree of obstruction at CD level rather than an alteration of LES relaxation which has been described by

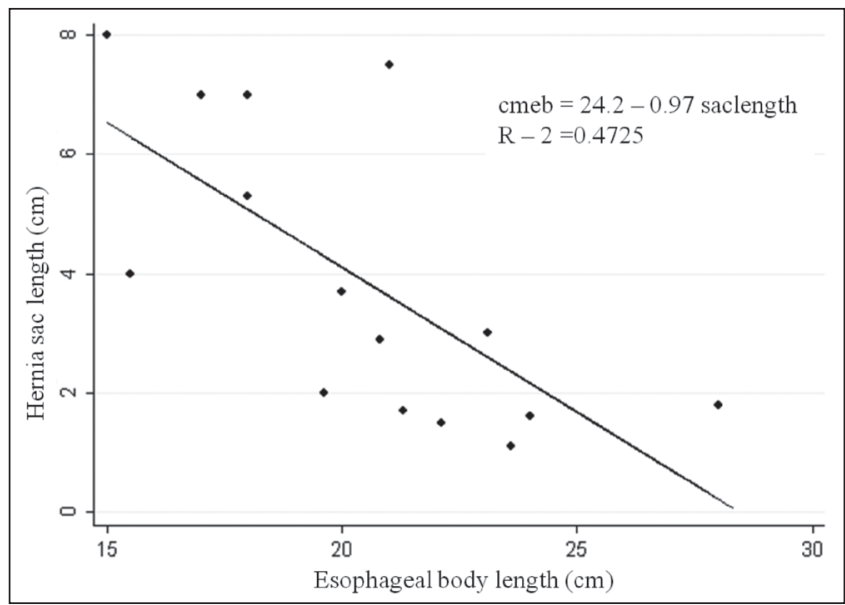

Fig. 2. Correlation between the length of the hernia sac and esophageal shortening (cmeb: Esophageal body length; saclength: Length of the hernia sac). 


\section{GEJ type and HRM results for LES}

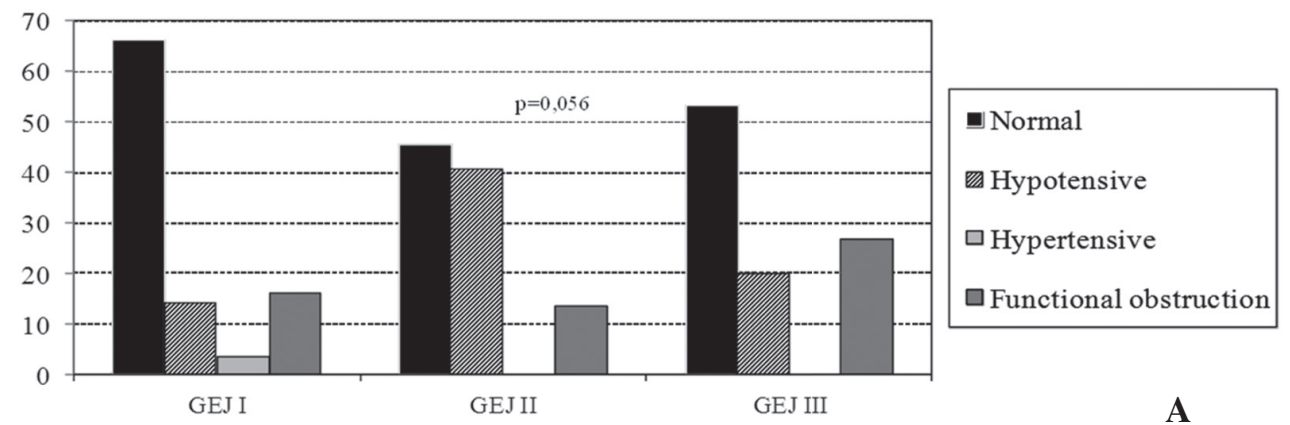

GEJ type and HRM resu lts for esophageal body

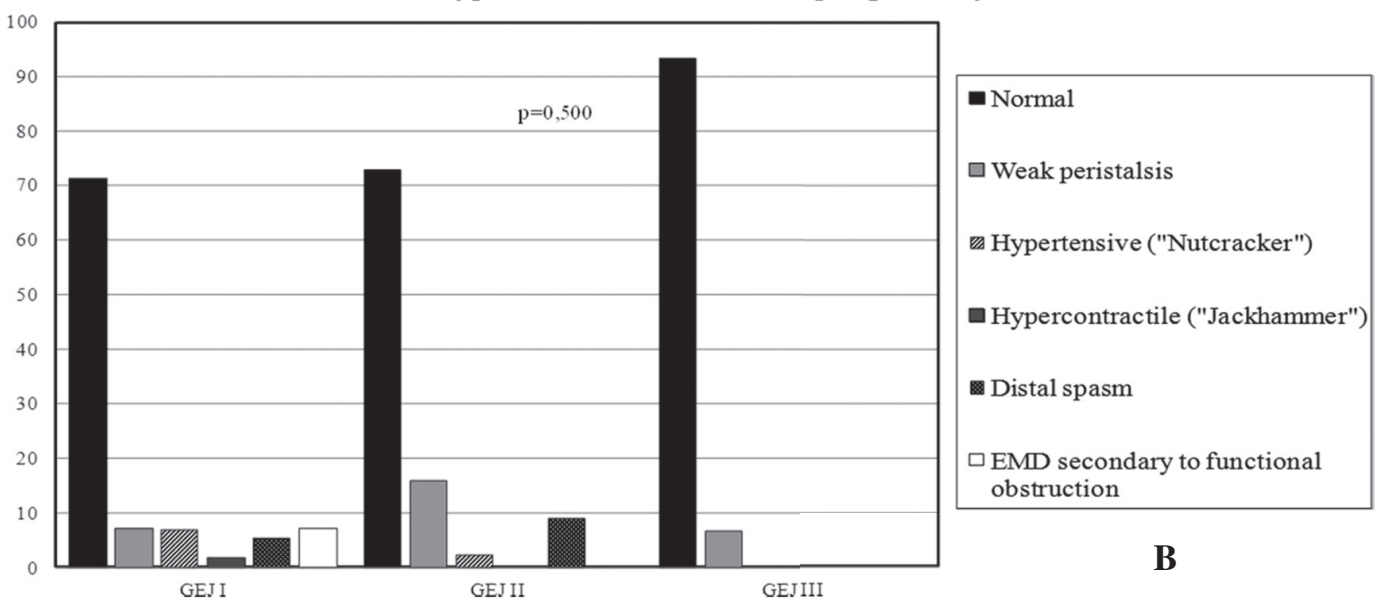

Fig. 3. Result of HRM for LES (A) and esophageal body according to the GEJ type (B) (EMD: Esophageal motor disorder).

other authors (21). Therefore, any alteration in the GEJ relaxation observed in large hiatal hernias may be caused to a greater extent by the anatomical distortion of the passage of the stomach to intrathoracic level (5).

Our study has some limitations, the most significant being the low number of patients with GEJ type III. This

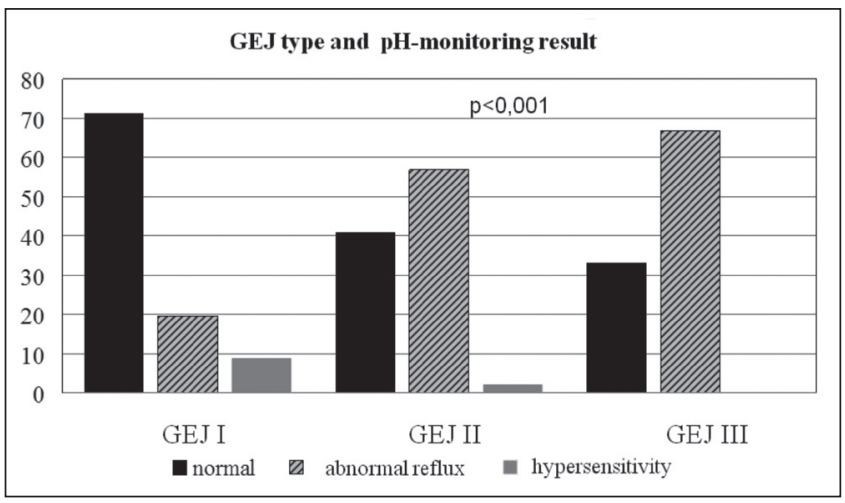

Fig. 4. Result of the pH-monitoring according to the GEJ type. was due in part to the restrictive inclusion criteria, as we only included patients with typical or atypical GER symptoms, having excluded those who also presented with dysphagia, as longer hernias might cause this symptom.

In conclusion, ageing, overweight and central obesity were risk factors for developing GEJ disruption, finding lower resting pressure, less esophageal length and greater acid exposure in the patients with GEJ type II and III. Those with GEJ type III (hiatal hernia) showed some differences in HRM parameters in the esophageal body, though this did not modify the final diagnosis.

\section{REFERENCES}

1. Goyal RK, Chaudhury A. Physiology of normal esophageal motility. J Clin Gastroenterol 2008;42:610-9.

2. Kwiatek MA, Pandolfino JE, Kahrilas PJ. 3D-high resolution manometry of the esophagogastric junction. Neurogastroenterol Motil 2011;23:e461-9.

3. Kahrilas PJ, Kim HC, Pandolfino JE. Approaches to the diagnosis and grading hiatal hernia. Best Pract Res Clin Gastroenterol 2008;22:60116. 
4. Bredenoord AJ, Weusten BL, Timmer R, Smout AJ. Intermittent spatial separation of diaphragm and lower esophageal sphincter favors acidic and weakly acidic reflux. Gastroenterology 2006;130:334-40.

5. Roman S, Kahrilas PJ, Kia L, D Luger, Soper, Pandolfino JE. Effects of large hiatal hernias on esophageal peristalsis. Arch Surg 2012;147:3527.

6. Kahrilas PJ, Peters JH. Evaluation of the esophagogastric junction using high resolution manometry and esophageal pressure topography. Neurogastroenterol Motil 2012;24(Suppl. 1):11-9.

7. Pandolfino JE, SK Ghosh, Zhang Q, Jarosz, Shah N, Kahrilas PJ. Quantifying EGJ and relaxation - high-resolution manometry with morphology: A study of 75 asymptomatic volunteers. Am j Physiol Gastrointest Liver Physiol 2006;290:G1033-40.

8. Ciriza-de-Los-Rios C, Canga-Rodriguez-Valcarcel F. High-resolution manometry and impedance-pH/manometry: Novel techniques for the advancement of knowledge on esophageal function and their clinical role. Rev Esp Enferm Dig 2009;101:861-9.

9. Pandolfino JE, Kim H, SK Ghosh, Clarke JO, Zhang Q, Kahrilas PJ. High-resolution manometry of the EGJ: An analysis of the crural diaphragm function in GERD. Am j Gastroenterol 2007;102:1056-63.

10. Tsuboi K, Hoshino M, Srinivasan A, Yano F, Hinder RA, DeMeester TR, et al. Insights gained from symptom evaluation of esophageal motility disorders: A review of 4,215 patients. Digestion 2012;85:23642.

11. Bredenoord AJ, Herbard GS. Technical aspects of clinical - high-resolution manometry studies. Neurogastroenterol Motil 2012;24(Suppl. 1):5-10.

12. Roman S, Kahrilas PJ, Boris L, K, D Luger Bidari, Pandolfino JE. High-resolution manometry studies are frequently imperfect but usually still interpretable. Clin Gastroenterol Hepatol 2011;9:1050-5.
13. AJ Bredenoord, Fox M, Kahrilas PJ, Pandolfino JE, Schwizer W, Smout AJ. Chicago classification criteria of esophageal motility disorders defined in high resolution esophageal pressure topography. Neurogastroenterol Motil 2012;24(Supl. 1):57-65.

14. Bodger K. Guidelines for oesophageal manometry and $\mathrm{pH}$ monitoring. BSG Guidelines in Gastroenterology 2006:1-11

15. Pandolfino JE, Zhang HQ, SK Ghosh, have A, C Boniquit, Kahrilas PJ. Transient lower esophageal sphincter relaxations and reflux: Mechanistic analysis using concurrent fluoroscopy and high-resolution manometry. Gastroenterology 2006;131:1725-33.

16. Mittal RK, Karstens, Leslie E, Babaei, Bhargava V. Ambulatory high-resolution manometry, lower esophageal sphincter lift and transient lower esophageal sphincter relaxation. Neurogastroenterol Motil 2012;24:40-6, e2.

17. Lee YY, Whiting JG, Robertson EV, Derakhshan MH, Smith D, McColl KE. Measuring movement and location of the gastroesophageal junction: Clinical and research implications. SCAND J Gastroenterol 2013;48:401-11.

18. Khajanchee YS, Cassera MA, Swanstrom LL, Dunst CM. Diagnosis of type I hiatus hernia: A comparison of high-resolution manometry and endoscopy. DIS Esophagus 2013;26:1-6.

19. Curci JA, Melman LM, Thompson RW, Soper NJ, Matthews BD. Elastic fiber in the supporting ligaments of the gastroesophageal junction depletion: A structural basis for the development of hiatal hernia. J Am Coll Surg 2008;207:191-6.

20. Pandolfino JE, El - Serag HB, Zhang Q, Shah N, SK Ghosh, Kahrilas PJ. Obesity: A challenge to esophagogastric junction integrity. Gastroenterology 2006;130:639-49.

21. Pandolfino JE, Kwiatek MA, Ho K, Scherer JR, Kahrilas PJ. Unique features of esophagogastric junction pressure topography in hiatus hernia patients with dysphagia. Surgery 2010;147:57-64. 